\title{
Period-Cohort Effects Models for Sexual Debut in Namibia
}

\author{
aLillian Pazvakawambwa, ${ }^{\mathrm{a}}$ Lawrence Kazembe, ${ }^{\mathrm{C}}$ Nelago Indongo \\ ${ }^{a}$ Department of Statistics and Population Studies, University of Namibia \\ ${ }^{b}$ Multi-Disciplinary Research Centre, University of Namibia, 340 Mandume Ndemufayo Avenue, \\ Pioneerspark, Windhoek, Namibia \\ Ipazvakawambwa@unam.na
}

\begin{abstract}
Early sexual debut is often associated with a number of social challenges. However, the hazard and risk factors of changing pattern of age at first sex have not been fully explained. This paper investigated the period-cohort effects by fitting flexible time-to-event models of sexual debut using retrospective crosssectional data of the 2000 and 2006-7 Namibian Health and Demographic Survey, to establish individual and structural effects, and simultaneously investigated spatial frailty effects, non-linear effects of age, cohort and period on the timing of sexual debut among women. The hazard of sexual debut reduced as the woman's year of birth increased suggesting a generational effect. The North Eastern parts of Namibia were associated with a higher risk of early sexual debut compared to all other regions. Intervention strategies should be multifaceted and involve not only schools and communities but individual family units as they have a bigger role to play in this regard.
\end{abstract}

Keywords: sexual debut, discrete time-to-event models, Namibia

\section{Introduction}

In most African settings, sexual activity begins at marriage. This is mainly because most African families are built on Christian beliefs like in Namibia where religion for more than $90 \%$ of the population is Christianity. However, with the increase in educational level there is an increase in premarital sex and premarital child-bearing as marriage is often delayed until completion of study programmes. It is also noted that there is a high level of teenage pregnancy signifying that many young girls start sex at an early age.

Early first sexual intercourse is often associated with unplanned adolescent motherhood, unwanted pregnancies (Hallert et al,2007; Kaestle et al,2005; Rostosky, Regnerus and Wright, 2003), abortions and infanticide, school drop-outs, risk of sexually transmitted infections including HIV, maternal mortality (Zaba et al.,2012; Pettifor et al,2004; Mcgrath et al, 2012; Tilahun and Ayele,20I3; Newell, 2008), and a general reduction of future life opportunities for the individual concerned (Hallert et al,2007). Early sexual intercourse may represent a life course transition that increases the chances of a longitudinal pattern of risky sexual activity, whose consequences may affect sexual functioning and relationship skills (Upadhyay and Hindin, 2007; Sandfort et al, 2008). Muharaj and Munthree (2007) found that in KwaZulu Natal, South Africa, nearly $46 \%$ of all sexually experienced young women reported that their first sexual encounter had been coerced. Those who had reported being coerced at first sex were significantly more likely to be black and living in an urban area, more likely to report having sexually transmitted infection (STI), and having experienced unintended pregnancy compared to those who had not been coerced at first sex. They noted that coercion at first sex is an important health problem that has a serious impact on the reproductive health and behaviour of young women.

Hallert et al. (2007) established that the median age at first sex had declined among males over the past 30 years but increased recently among females. A number of factors have been associated with sexual debut. Huschek et al (2010) established that characteristics of parent modernity were related to delayed entry into union. Having parents with lower human capital, coming from a larger family, and having a parent with certain backgrounds resulted in significantly different rates of union formation. The influence of parental human capital was at least partly mediated by the child's own educational attainment. When parents made household decisions jointly, sons reported delaying first sex. In households in which mothers had higher status, daughters reported delayed first sex. The results indicated that long-term positive effects on children, particularly delaying first sex, occur in families in which parental decision making is cooperative and in which women have higher status. Contact with non-co-ethnic peers resulted in postponement of starting a first union, and going to school with natives resulted in slower rates of entry into first union. Seiving etal (2006) revealed 
that the higher proportion of a youth's friends who were sexually experienced, the greater the odds of sexual debut. The odds were also elevated among youth who believed that they would gain their friends' respect by having sex. Age at first sex is also associated with peri-urban residence (versus rural), ever use of alcohol, knowing at least one person who had HIV, while school attendance had a significant protective effect (Mcgrath et al,20I2); employment, religion (Zaba et al.,20I2), and ethnicity(Mueller etal, 2008).

\section{Justification}

The time to first sex, is usually measured in years and is assumed to be continuous and usually modelled by classical parametric regression methods. The Cox proportional hazards function is well known for modelling event histories (Baschieri and Hinde, 2007). Unfortunately the time variable is measured on a continuous scale and is based on the proportional hazards assumption. This assumption is violated in most cross-sectional survey data which is based on retrospective studies, data is measured in discrete time, where there is recall bias and a lot of tied observations (Gayawan and Adebayo, 20/3). Furthermore, this approach may not be suitable for estimating small area effects and at the same time adjusting for other covariates especially when the effects of the covariates are non-linear or timevarying (Manda and Meyer, 2005; Gayawan and Adebayo, 2013). Kneib (2006) proposed to address this challenge by assuming that an event occurs over an interval of time such that the heavily tied survival times are incorporated by introducing larger intervals for the heaped observations.

This paper investigated the age- period-cohort effects by fitting a flexible, time-to-event models of age at first sex, using a case-study of data from Namibia. Study findings will aid the design strategies for delaying sexual debut. There has been debate that sexual debut has recently declined (Dude, 2005; Guo et al., 20I2; Martinez et al, 20II; Mmbaga, et al, 2012). However, the hazard and risk factors of changing pattern of age at first sex have not been fully

$$
\eta_{i}(t)=v_{i}^{\prime} Y+g_{o}(t)+\sum_{j=1}^{J} f_{j}\left(x_{i j}\right)+f_{\text {spat }}\left(s_{i}\right)+b_{g i}
$$

where $\eta_{i}(t)$ is the predictor, $f_{j}\left(x_{i j}\right)$ is the non-linear effect of continuous covariates $x_{j}$, and $f_{s p a t}(s)$ is the spatial effect. The vector of linear effects is denoted by $\gamma$ while $b_{g}, g \in\{1, \cdots, G\}$ are uncorrelated individual or group specific frailties. A structured additive model for discrete time- to-event outcome was used to establish individual and structural effects, and simultaneously investigate non- explained. In addition, the actual pattern of risk factors of early sexual debut are largely unknown in Namibia

\section{Data \& Methods \\ Data}

This study is based on the 2000 and 2006/7 Namibia Demographic and Health Survey (DHS). DHS is a national survey drawn on using a multistage cluster sampling. At first stage, a random sample of enumeration areas (EA), which are primary sampling units, was chosen from the census sampling frame. In Namibia, the following procedure was used. From the selected EAs, households were systematically drawn. Only women of reproductive age (I5-49 years), in the selected households, were interviewed using a face-to-face questionnaire. The questionnaire included variables on individual bio-demographic factors, household characteristics, history of marital unions and births. Final samples included in the analysis were respectively, 6755 from the 2000 survey and 9800 women, from the 2006/7 round of surveys. The DHS is a nationally representative sample, being secondary data, however, any errors in the data collection process will be inherited.

\section{Statistical Modelling}

The standard procedure for examining the effects of covariates $\left(v_{i}\right)$ on survival times $(T)$ is the Cox proportional hazard model where the multiplicative structure is assumed for the hazard rate, $\gamma$ is a vector of regression coefficients and $\lambda_{0}(t)$ is the baseline hazard rate at observed time $(t)$. The baseline hazard rate is re-parameterized through $g_{0}=\log \left(\lambda_{0}(t)\right)$ and covariates are partitioned

$$
\lambda_{i}=\lambda\left(t, v_{i}\right)=\lambda_{0}(t) \exp \left(v_{i}^{\prime}, \gamma\right)
$$

into groups of different types to extend the Cox model to a semi-parametric hazard rate model so that $\lambda_{i}(t)=\exp \left(\eta_{i}(t)\right), i=1,2, \cdots, n$ is a geoadditive predictor predictor of the form linear effects of age, cohort and period on the timing of first sex among women. An extended geo-additive Cox model that addresses arbitrary combinations of left, right and interval censoring schemes and relaxes the proportional hazards assumption by allowing all covariates to be piecewise constant i.e. time varying was further proposed by Kneib (2006). Other extensions of geo-additive models have been widely 
developed and adopted (Adebayo and Farhmeir 2005; Hennerfeind et al, 2006; Khatab and Fahrmeir, 2009; Wand, Whitaker and Ramjee,20II; Nkurunziza, Gerbhhardt and Pilz,20I I; Claudio et al, 2012; Olubiyi and Olubusoye, 20I3).

The predictor, $\eta_{i}(t)$ can be expressed in matrix notation if we let $\boldsymbol{\eta}=\left(\eta_{1}, \eta_{2}, \cdots, \eta_{n}\right)^{\prime}$ denote the prediction vector, and let $\boldsymbol{g}_{\boldsymbol{l}}=\left(g_{l}\left(t_{1}\right), \cdots,\left(g_{l}\left(t_{n}\right)\right)^{\prime}\right.$ denote the evaluation of functions $g_{l}(t), \boldsymbol{f}_{\boldsymbol{j}}=$ $\eta=V \lambda+Z_{1} B_{1}+\cdots Z_{p} B_{p}$. $\left(f_{j}\left(x_{1 j}\right), \cdots f_{j}\left(x_{n j}\right)\right)^{\prime}$, the vector of evaluations of the functions $f_{j}\left(x_{j}\right)$, $\boldsymbol{f}_{\text {spat }}=\left(f_{\text {spat }}\left(s_{1}\right), \cdots, f_{\text {spat }}\left(s_{n}\right)\right)^{\prime}$, the vector of spatial effects and $\boldsymbol{b}=\left(b_{g 1}, \cdots b_{g n}\right)^{\prime}$ the vector of uncorrelated random effects. These vectors can be expressed as a matrix product of a design matrix $\mathbf{Z}$ and vector of parameters $B$ to give

The likelihood of $\vartheta=\left(\boldsymbol{\lambda}^{\prime}, \boldsymbol{B}_{1}{ }^{\prime}, \cdots, \boldsymbol{B}_{\boldsymbol{p}}{ }^{\prime}\right)$ for an interval censored observation is given by

$$
L_{i}(\vartheta)=\exp \left(-\int_{0}^{T_{j}} \lambda(\boldsymbol{t}) \boldsymbol{d} \boldsymbol{t}\right)\left(1-\exp \left(-\int_{T_{l}}^{T_{u}} \lambda(\boldsymbol{t}) \boldsymbol{d} \boldsymbol{t}\right)\right)
$$

The model was estimated using Bayesian inference. Priors for all parameters were assigned under the Bayesian approach (Lang and Brezger, 2004; Kneib and Fahrmeir, 2007). Diffuse priors were assumed for fixed parameters, while for the baseline effect $g_{o}(t)$ and the non-linear effects $f_{j}\left(x_{i j}\right)$, Bayesian Pspline prior was assumed. These allowed for nonparametric estimation of $f$ as a linear combination of basis function (B-splines) $f(z)=$ $\sum_{t=1}^{m} \alpha_{t} \beta_{t}(z)$, where $\beta_{t}(z)$ are B-splines and the coefficient of $\alpha_{t}$ are further defined to follow a second order Gaussian random walk smoothness priors

$$
\begin{aligned}
\alpha_{2}=2 \alpha_{j-1}-\alpha_{j-2}+\epsilon_{1} \\
\\
\quad\left[\boldsymbol{f}_{\text {spat }}(\boldsymbol{s}) \mid \boldsymbol{f}_{\text {spat }}(\boldsymbol{t}) ; \boldsymbol{t} \neq \boldsymbol{s}, \boldsymbol{\tau}^{2}\right] \sim \boldsymbol{N}\left(\sum_{\boldsymbol{t} \in \boldsymbol{\partial}_{\boldsymbol{s}}} \frac{\boldsymbol{f}_{\text {spat }}(\boldsymbol{t})}{\boldsymbol{N}_{\boldsymbol{s}}}, \frac{\boldsymbol{\tau}^{2}}{\boldsymbol{N}_{\boldsymbol{s}}}\right)
\end{aligned}
$$

where $N_{s}$ is the number of adjacent sites and $t \in \partial_{s}$ denotes that site $t$ is a neighbour of site $s$. The prior defines areas as neighbours if they share a common boundary and neighbouring areas are assumed to have similar patterns. The conditional mean of $f_{\text {spat }}(s)$ is an average function of evaluations $f_{\text {spat }}(t)$ of neighbouring sites $t$, with $\tau^{2}$ controlling the amount of spatial smoothness. In order to be able to estimate the smoothing parameters for non-linear and spatial effects, highly dispersed but proper hyperpriors are assigned to them. Hence, for all variance components, an inverse gamma distribution with hyper-parameters $a$ and $b$ is chosen e.g. $\tau^{2} \sim I G(\boldsymbol{a}, \boldsymbol{b})$. Standard choices for the hyper parameters are $a=l$ and $b=0.005$ or $a=b=0.001$. Evaluation of the posterior distribution of the model parameters was based on Empirical with i.i.d. errors $\epsilon_{1} \sim N\left(0, \tau^{2}\right)$. The variance $\tau^{2}$ controls the smoothness of $f$. Assigning a weakly informative inverse Gamma prior $\tau^{2} \sim I G(\epsilon, \epsilon)$, with $\epsilon$ very small, it is estimated jointly with the basis function coefficients.

Random effects $\left(b_{g i}\right)$ were modelled by assuming exchangeable normal priors, $b_{i j} \sim N\left(0, \tau_{b}^{2}\right)$, where $\tau_{b}^{2}$ is a variance component that incorporates overdispersion and heterogeneity. For the spatial effects $f_{\text {spat }}(s)$, we chose a Gaussian Markov random field prior, which is commonly used in spatial statistics (Beag, York and Mollie, 199I), given as
Bayesian inference. This used a restricted maximum likelihood proposal which adopts a generalized mixed methodology approach (Kneib and Fahrmeir, 2007). Detailed numerical methods of implementing survival time models are described in the reference manuals of BayesX (Fahrmeir and Tutz, 200I; Belitz et al., 2009; ). Model diagnostics were based on the Akaike Information Criterion (AIC) and the Bayesian Information criteria (BIC). The best model is the one with the smallest $\mathrm{AIC}$ and $\mathrm{BIC}$. AIC and $\mathrm{BIC}$ regulate the trade-off between the goodness of fit of the model and the complexity by imposing a penalty discourages over-fitting (increasing the number of free parameters in the data-generating process). All analyses were carried out in BayesX, a software for Bayesian inference in Structured Additive Regression models - version 2.0.I (Berlitz et al., 2009). 


\section{Results}

The background characteristics of the sample after data restructuring are presented in Table I.

Table I: Sample Characteristics of women $(\mathrm{N}=82795)$

\begin{tabular}{|c|c|c|}
\hline Variable & $\underline{\mathbf{N}}$ & Percentage \\
\hline \multicolumn{3}{|l|}{ Age-group } \\
\hline $15-19$ & 18175 & 22.0 \\
\hline $20-24$ & 15970 & 19.3 \\
\hline $25-29$ & 13350 & 16.1 \\
\hline $30-34$ & 12150 & 14.7 \\
\hline $35-39$ & 9325 & 11.3 \\
\hline $40-44$ & 8025 & 9.7 \\
\hline $45-49$ & 5800 & 7.0 \\
\hline \multicolumn{3}{|l|}{ Period } \\
\hline 2000 & 33775 & 40.8 \\
\hline $2006 / 7$ & 49020 & 59.2 \\
\hline \multicolumn{3}{|l|}{ Cohort } \\
\hline $1950-1964$ & 15100 & 18.3 \\
\hline $1965-1974$ & 21770 & 26.3 \\
\hline |975-1984 & 29575 & 35.7 \\
\hline 1985-1992 & 16350 & 19.7 \\
\hline \multicolumn{3}{|l|}{ Region } \\
\hline Zambezi & 4860 & 5.9 \\
\hline Erongo & 5985 & 7.2 \\
\hline Hardap & 5220 & 6.3 \\
\hline !Karas & 4890 & 5.9 \\
\hline Kavango( East and West) & 7525 & 9.1 \\
\hline Khomas & 7730 & 9.3 \\
\hline Kunene & 8105 & 9.8 \\
\hline Ohangwena & 4660 & 5.6 \\
\hline Omaheke & 5420 & 6.5 \\
\hline Omusati & 6905 & 8.3 \\
\hline Oshana & 7920 & 9.6 \\
\hline Oshikoto & 7010 & 8.5 \\
\hline Otjozonjupa & 6565 & 7.9 \\
\hline \multicolumn{3}{|l|}{ Place of Residence } \\
\hline Rural & 45260 & 54.7 \\
\hline Urban & 37537 & 45.3 \\
\hline \multicolumn{3}{|l|}{ Level of education } \\
\hline Primary or No Formal & 31795 & 38.4 \\
\hline Secondary or Higher & 51000 & 61.6 \\
\hline \multicolumn{3}{|l|}{ Religion } \\
\hline Protestant & 61985 & 74.9 \\
\hline Catholic & 18835 & 22.8 \\
\hline No religion & 1150 & 1.4 \\
\hline Other & 475 & 0.6 \\
\hline Missing & 350 & 0.4 \\
\hline \multicolumn{3}{|l|}{ Wealth Index } \\
\hline Poor & 14490 & 17.5 \\
\hline Poorer & 14515 & 17.5 \\
\hline Middle & 17425 & 21.0 \\
\hline Richer & 18640 & 22.5 \\
\hline Richest & 14910 & 18.0 \\
\hline Missing & 2815 & 3.4 \\
\hline
\end{tabular}


Five hazard models were explored to establish the effect of observed and unobserved heterogeneity on the timing of sexual debut in Namibia. The fitted models were defined as follows:

Model I: $\eta_{1}=f($ baseline $)$

Model 2: $\eta_{2}=f($ baseline $)+$ trend

Model 3: $\eta_{3}=f($ baseline $)+$ trend + fixed $($ cat $)+$ fixed(Region $)$

Model 4a: $\quad \eta_{4}=f($ baseline $)+$ trend + fixed + nonlinear + random (Region)

Model 4b: $\quad \eta_{4}=f($ baseline $)+$ trend + fixed + nonlinear $\left.+\operatorname{spatial(Region}\right)$

Model 5: $\eta_{5}=f($ baseline $)+$ trend + fixed $+\operatorname{nonlinear}+\operatorname{random}($ Reg $)+\operatorname{spatial}($ Region $)$

The nesting structure of the models is summarized in

Table 2. The symbol $(x)$ indicates that the component was included in the model.

Table 2: Nesting structure of models I to 5.

\begin{tabular}{|l|l|l|l|l|l|l|}
\hline $\begin{array}{l}\text { Model } \\
\text { specification }\end{array}$ & $\begin{array}{l}\text { Baseline } \\
g_{0}(t)\end{array}$ & $\begin{array}{l}\text { Time } \\
\text { I }\end{array}$ & $\begin{array}{l}\text { Fixed effect } \\
\boldsymbol{V}_{\boldsymbol{j}}\end{array}$ & $\begin{array}{l}\text { Non-linear } \\
\text { effect }\end{array}$ & $\begin{array}{l}\text { Random } \\
\text { effect }\end{array}$ & Spatial effect \\
\hline 2 & $\mathrm{X}$ & & & & & \\
\hline 3 & $\mathrm{X}$ & $\mathrm{X}$ & & & & \\
\hline $4 \mathrm{a}$ & $\mathrm{X}$ & $\mathrm{X}$ & $\mathrm{X}$ & & & \\
\hline $4 \mathrm{~b}$ & $\mathrm{X}$ & $\mathrm{X}$ & $\mathrm{X}$ & $\mathrm{X}$ & $\mathrm{X}$ & \\
\hline 5 & $\mathrm{X}$ & $\mathrm{X}$ & $\mathrm{X}$ & $\mathrm{X}$ & & $\mathrm{X}$ \\
\hline
\end{tabular}

Table 3 shows the model diagnostic statistics for all the fitted models. Model 5 had the smallest AIC and
$\mathrm{BIC}$ was therefore chosen as the best model and was considered for further discussion.

Table 3: Model Diagnostic Statistics.

\begin{tabular}{|l|l|l|l|l|}
\hline Model specification & -2 Log-Likelihood & df & AIC & BIC \\
\hline I & 68530.1 & 9.41 & 68548.9 & 68635.8 \\
\hline 2 & 68527.1 & 10.40 & 68547.9 & 68643.9 \\
\hline 3 & 65068.6 & 31.71 & 65132.0 & 65423.7 \\
\hline $4 \mathrm{a}$ & 64672.8 & 30.86 & 64734.6 & 65018.4 \\
\hline 4b & 64668.7 & 32.28 & 64733.2 & 65030.2 \\
\hline $5^{*}$ & 64671.1 & 30.52 & 64732.1 & 65012.9 \\
\hline
\end{tabular}

*Best model

\section{Trend and Fixed Effects}

Table 4 displays the estimates of posterior modes of the fixed effect parameters for the baseline and the best model (Model 5). Presented are the posterior modes, standard deviations and $95 \%$ confidence intervals. Results indicate that compared to 2000, there has been an increase in the relative risk in sexual debut. Compared to women in rural areas, urban women are at higher risk of early sexual debut even though the differentials were not significant. With regard to the highest educational level of the woman, a statistically not significant higher risk of early sexual debut was observed for those women with secondary or higher education compared to those with primary or no formal education. Compared to the poor women, women in the middle, and those in the rich wealth index categories also had an insignificantly higher risk of early sexual debut. Religion did not seem to impact on sexual debut. Even though Catholic women were at a higher risk of early sexual debut compared to their protestant counterparts, the differentials were not significant. 
Table 4: Estimates of posterior modes of the fixed effect parameters for the baseline and the best model

\begin{tabular}{|c|c|c|c|c|c|c|c|c|}
\hline \multirow[t]{2}{*}{ Variable } & \multicolumn{4}{|c|}{ Results for Model I } & \multicolumn{4}{|c|}{ Results for model 5 (best model) } \\
\hline & \multirow{2}{*}{$\begin{array}{l}\text { Posterior } \\
\text { Mode } \\
-2.037^{*} \\
\end{array}$} & \multirow{2}{*}{$\begin{array}{l}\text { SD } \\
0.096\end{array}$} & \multirow{2}{*}{$\begin{array}{l}95 \% \\
\text { interval } \\
-2.226^{*}\end{array}$} & Confidence & \multirow{2}{*}{$\begin{array}{l}\text { Mean } \\
-2.197^{*}\end{array}$} & \multirow{2}{*}{$\begin{array}{l}\text { SD } \\
0.136\end{array}$} & \multirow{2}{*}{$\begin{array}{l}95 \% \\
\text { interval } \\
-2.463 \\
\end{array}$} & Credible \\
\hline Constant & & & & -1.848 & & & & -1.931 \\
\hline \multicolumn{9}{|l|}{ Period } \\
\hline 2000 (ref) & & & & & 0.000 & & & \\
\hline $2006 / 7$ & & & & & 0.195 & 0.195 & -0.187 & 0.577 \\
\hline \multicolumn{9}{|l|}{ Place of Residence } \\
\hline Rural (ref) & & & & & 0.000 & & & \\
\hline Urban & & & & & 0.000285 & 0.0262 & -0.0486 & 0.0543 \\
\hline \multicolumn{9}{|l|}{ Level of education } \\
\hline $\begin{array}{ll}\text { Primary or } & \text { No } \\
\text { Formal (ref) } & \end{array}$ & & & & & 0.000 & & & \\
\hline $\begin{array}{l}\text { Secondary or } \\
\text { Higher }\end{array}$ & & & & & 0.000604 & $0.024 I$ & -0.0533 & 0.041 \\
\hline \multicolumn{9}{|l|}{ Wealth Index } \\
\hline Poor(ref) & & & & & 0.000 & & & \\
\hline Middle & & & & & 0.0242 & 0.0298 & -0.0342 & 0.062 \\
\hline Rich & & & & & 0.0120 & 0.033 & -0.052 & 0.076 \\
\hline \multicolumn{9}{|l|}{ Religion } \\
\hline Protestant (ref) & & & & & 0.000 & & & \\
\hline Catholic & & & & & 0.0145 & 0.024 & -0.033 & 0.062 \\
\hline
\end{tabular}

\section{Baseline and non-linear effects}

Figure I (a-c) displays the estimated posterior modes together with their corresponding $95 \%$ confidence bands for the non-linear effects of time to first sex (baseline effect); respondent's year of birth (cohort effect); and respondent's age (age effect). The baseline effect exhibited the same pattern for all the explored models. From as early as the age of 8 , the risk of sexual debut is high until the age of around 30 years, where it begins to drop, first slowly until age 40, after which it deeps down sharply. Beyond age forty, as expected, a lower risk is observed since most women will have experienced the event by this period. From the plots, it is evident that the effects of the respondent's cohort effect and the respondent's age were non -linear, thus an assumption of linear effect would have given misleading results and interpretations. The results also indicate a cohort shift such that the hazard of early sexual debut is reduced as the as the woman's year of birth increases, suggesting a generational effect. The hazard of sexual debut initially increases steeply from age 15 and peaks at about age 21 . Thereafter, the risk of sexual debut steadily declines with the respondent's age.

Figure 1a) Non-linear effect of age at first sex (baseline effect) with $80 \%$ and $95 \%$ Confidence Interval

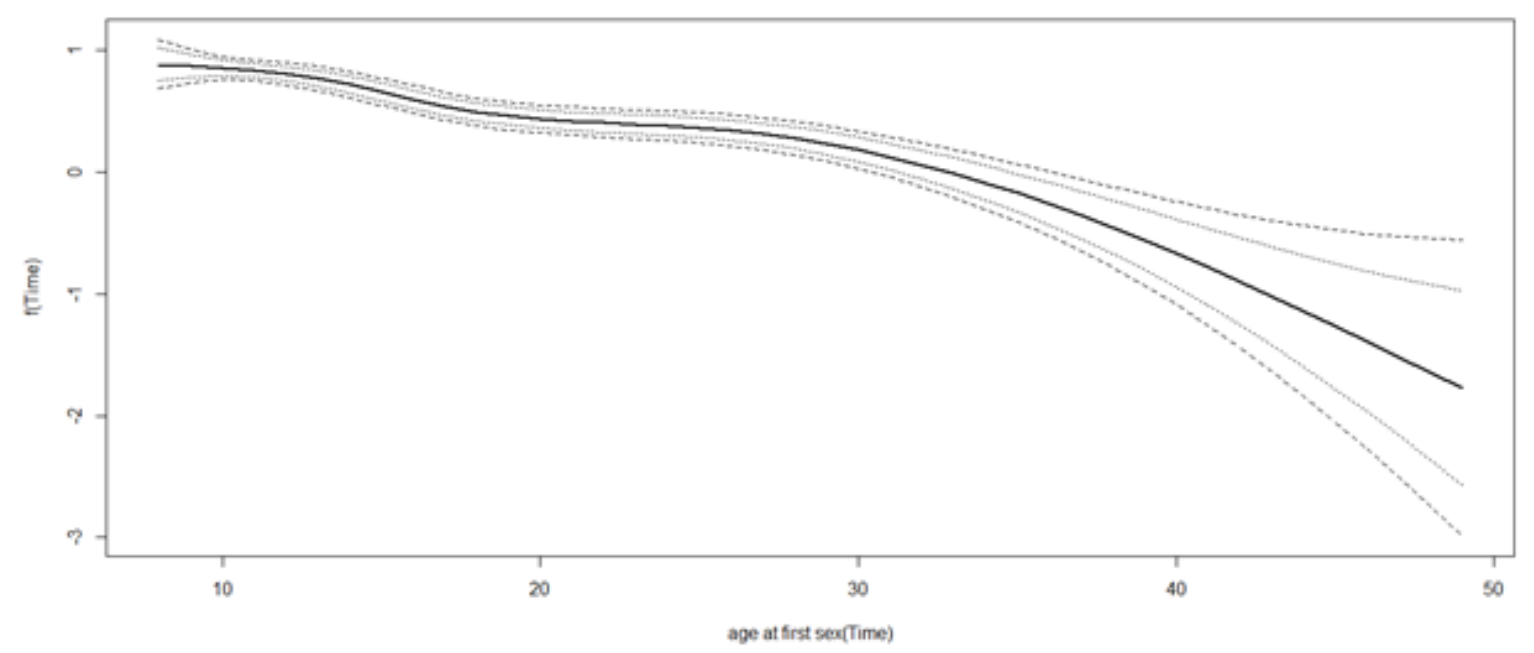



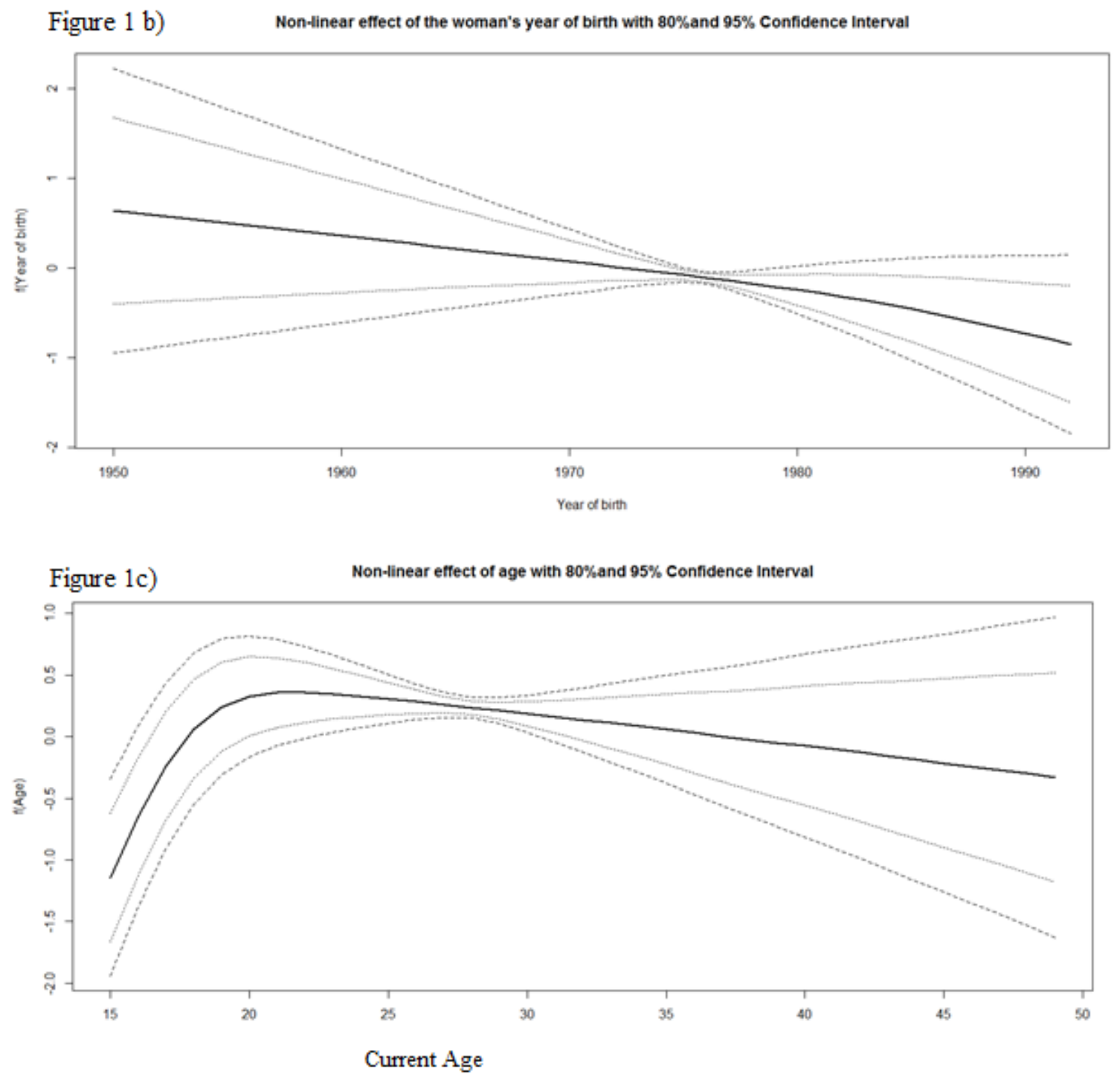

\section{Spatial effects}

The spatial effects of model 5 (the best model) are shown in Figure 2. The first two maps show the location of the $80 \%$ and $95 \%$ confidence intervals while the third map displays the posterior modes. The confidence intervals are used to assess the significance of the spatial effect. In this analysis, regions with white colour are significantly associated with higher risk of first sex (i.e. the $80 \% / 95 \%$ confidence interval lies on the positive side.); regions with black colour are significantly associated with lower risk (the $80 \% / 95 \%$ confidence interval lies on the negative side), while the risk is not significant in regions with grey colour (the $80 \% / 95 \%$ confidence interval includes zero).

The $80 \%$ confidence interval suggest that the North Eastern part of Namibia (Kavango and Zambezi regions) are associated with a high risk of early sexual debut, while those in Omusati and Oshana regions are associated with low risk. The risk of early first sex is not significant in the rest of the regions.The $95 \%$ confidence intervals suggest that only the Zambezi region associated with a high risk of early sexual debut, while the risk of early first sex is insignificant in all other regions.

Figure 2, showing the posterior modes also indicates that the North Eastern regions, followed by the central regions of Namibia are associated with a higher risk of early sexual debut. It is interesting to observe that the Southern regions and the North Western regions are associated with a relatively lower risk of early sexual debut. 
Figure 2: Non-linear spatial effects for age at first sex. Shown are log hazard plotted at regional level.

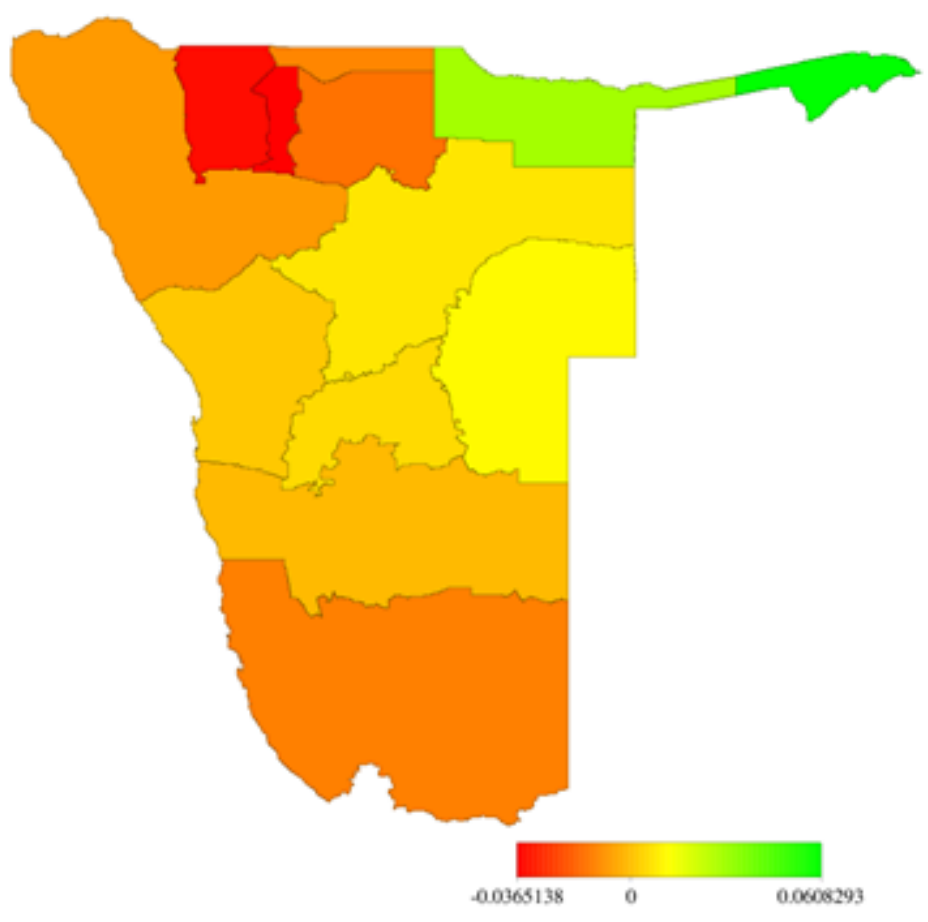

Figure 3: Significance maps of spatial effects for estimates in Fig 4: (a) $80 \%$ credible interval; and (b) $95 \%$ of confidence interval

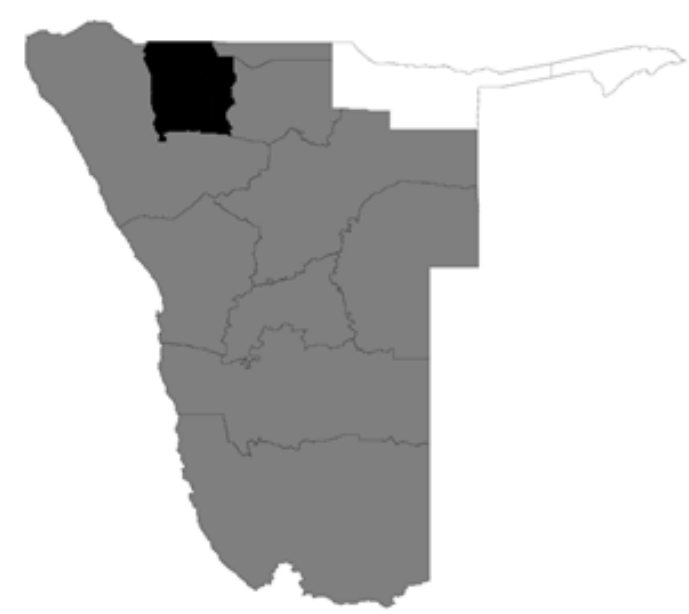

\section{Discussion}

This paper employed a structural additive regression model for discrete time-to-event outcome, a procedure which allows simultaneous modelling of fixed, non-linear, unobserved heterogeneity and spatial effect within a single framework, to examine age, period and cohort effects on the timing of first sex among women in Namibia.

From as early as the age of 8 , the risk of sexual debut peaked at 21 years of age and was still high until the age of around 30 years, and then dropped until age 40, after which it dipped down sharply. In South Africa, Bakilana (2005) established that the peak of the rate of entry into sexual relations

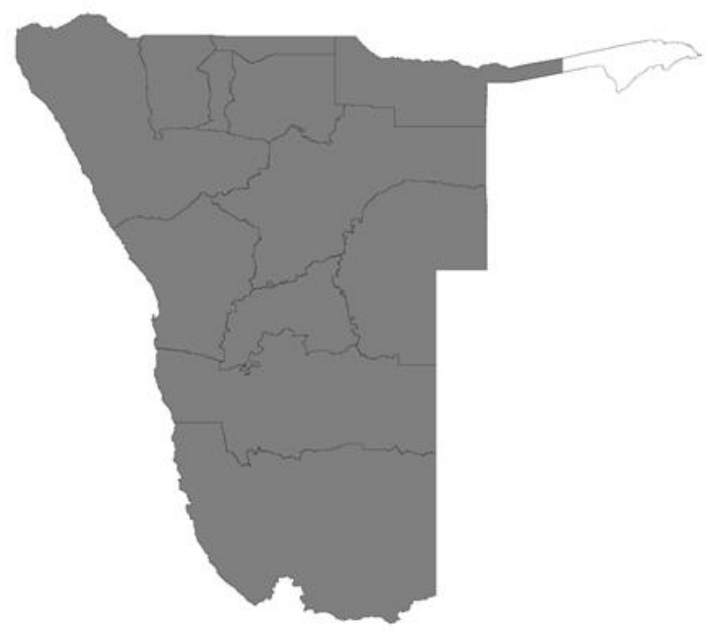

occurred at age 18 and that virtually all the women had had their sexual debut by age 23 . In contrast, younger age was strongly related to earlier age at first sex in Spain (de Sanjose et al., 2008). Even though the age at first sex increase between 2000 and 2006/7, the period effect was not significant. Zaba et al. (2004) also established a slow rise in the age at first sex in six African countries. For Namibia, a clear pattern may emerge as more survey data becomes available.

Results also indicated a cohort shift with the hazard of early sexual debut being reduced as the woman's year of birth increased. Similar results were 
obtained in Tanzania (Zaba et al., 2009) and Uganda (Slaymaker et al., 2009), where women who were born after 1970, on average, had their sexual debut at a later age than those born earlier. On the other hand, younger cohorts of women in South Africa were entering into sexual relations at earlier ages than older women (Bakilana, 2005). However, the age at sexual debut did not differ by birth cohort in Northern Malawi (Glynn et al., 20l0). The reduction in the risk of first sex as the year of birth increased in Namibia could be explained by generational differentials brought about by urbanization, dynamism of culture, values and norms and weakening traditional frameworks (Harding and Jencks ,2003; Gayaman and Adebayo, 2013 ).

The non-linear association exhibited by the age at first sex and the continuous covariates clearly indicates that an assumption of linear association of these continuous variables would have led to misleading results, and these could have adverse effects on policy recommendations. The structured additive regression model enabled the specification of the predictor structure in a more flexible manner so that all relationships could be appropriately estimated.

Results of spatial analysis revealed that age at first sex varied though not significantly, according to region, with women from the Zambezi and Kavango regions exhibiting higher risk of early sexual debut compared to all other regions. Elendou-Enyegue and Magazi (20II) found teenage pregnancy to be relatively high (34\%) among the 15 to 19 year olds in Kavango region, which suggests high prevalence of unprotected, early sexual debut. The authors established that very little of the fertility was wanted, and most of the teens in the area wished to delay first birth and even desired fewer children. It may be necessary in further research to assess whether these adolescent sexual activities leading to such high pregnancy rates are not coerced as established by Muharaj and Munthree (2007) in KwaZulu Natal, South Africa, and Uganda (Koenig, et al.,2004) so that appropriate intervention policy can be developed for policy.

\section{Conclusions}

Age, period and cohort effects in the timing of first sex were evident among women in Namibia. Efforts to discourage early sexual debut should be stepped up especially in North-Eastern Namibia. Intervention strategies should not only target schools and the wider community in isolation, but should involve the individual family units as they have a bigger role to play in this regard.

\section{Acknowledgements}

The authors acknowledge permission by Measure DHS and the Namibia Ministry of health and Social Services to use the data analyzed in this study. This research was made possible through funding from UNFPA and the University of Namibia.

\section{References}

Bakilana, A. (2005). Age at sexual debut in South Africa, African Journal of Aids Research, 4 (I) I-5. Doi: $10.2989 / 16085900509490335$.

Baschieri, A. and Hinde A. (2007). The proximate determinants of fertility and birth intervals in Egypt: An application of calendar data, Demographic Research 16 (3) 59-96. doi: 10.4054/DemRes.2007.16.3

Belitz, C., Brezger, A., Kneib, T. and Lang, S. (2009). Software for Bayesian Inference in Structured and Additive Regression Models. Version 2.0.I. http://www.stat.uni-muenchen.de/ bayesx.

Besag, J., York, Y., and Mollie, A. (199I). Bayesian image restoration with two applications in spatial statistics (with discussion). Annals of the Institute of Statistical Mathematics, 43 (I0) I-20. Doi: I 0. I007/BF00 I 6466.

Claudio,F., Mar, R., Carmen, C., Kneib, T.,Guadalupe, G.and Luis, C.(20I2). Flexible geoadditive survival analysisof non-Hodgkin lymphoma in Peru, Statistics and Operations Research Transactions (SORT), 32(2) 22I-230

Cotalbiano and Castiglioni M. (2008). Changing family formation in Nepal: Marriage, Cohabitation and First sexual Intercourse, International Family Planning perspectives, 34 (I) 30-39.

De Sanjose, S., Cortes, X.,Mendez, C., Puig-Tintore, L., Torne,A., Roura, E., Bosch, F.X., Castellesague, X. (2008). Age at sexual initiation and number of sexual partners in the female Spanish population: Results from the AFRODITA Survey, European Journal of Obstetrics \& Gynaecology and Reproductive Biology, I 40 (2) 234-240.

Eloundou-Enyegue, P.M. and Magazi, S. (20II). Teenage pregnancy in Kavango region: Contributing factors and program recommendations. The Global Health Technical Assistance Project. Report No. I I-0 I-525.

Gayawan E. and Adebayo S.B. (20/3). A Bayesian semi-parametric multilevel survival modelling of age at first birth in Nigeria, Demographic Research, 28 (45) I339-I 372.

Glynn, J.R., Kayuni, N., Floyd, S.,Banda, E., FrancisChizororo, M., Tanton, C., Molesworth, A., Hemmings, J., Crampin, A.C., and French, N. (20/0).Age at menarche, schooling, and sexual 
debut in Northern Malawi, PLOS ONE, 5 (12): el5334 doi: 10.137//journal.pone.00I5334.

Hallett T.B, Lewis JJ, Lopman BA, Nyamukapa CA, Mushati P, Wambe M, Garnett GP, Gregson S.(2007). Age at first sex and HIV infection in rural Zimbabwe, Studies in Family Planning, 38(I) I10.

Harding, J. and Jencks, C. (2003). Changing attitudes towards premarital sex: Cohort, period and Aging effects, The Public Opinion Quarterly, 67 (2)2II226.

Hennerfeind, A., Brezger, A. and Fahrmeir, L. (2006). Geo-additive survival models, Journal of the American Statistical Association, 101(475) 10651075.

Huschek, D., Liefbroer, A.C. and De Valk, H.A.G.(20/0). Timing of first union among second generation Turks in Europe: The role of parents, peers and institutional context, Demographic Research, 22 (I6) 473-504

Kaestle C., Halpern C.T., Miller W.C. and Ford C.A.(2005). Young age at first sexual intercourse and sexually transmitted infections in adolescents and young adults, American Journal of epidemiology, I6I (8) 774-780.

Khatab, K., Fahrmeir, L. (2009). Analysis of childhood mortality with geo-additive probit and latent variable model: A case study of Egypt, American Journal of Tropical Medicine and Hygiene, 8I (I) II6-28.

Kneib, T. (2006). Mixed model based inference in geo-additive hazard regression for inter-censored survival times. Computational Statistics and Data $\begin{array}{lllll}\text { Analysis } 5 \mathrm{I} & \text { (2) 777-792. doi }\end{array}$ 10.1016/j.csda.2006.06.019.

Kneib, T. and Fahrmeir, L. (2007). A mixed model approach for geo-additive hazard regression, Scandinavian Journal of Statistics, 34 (I) 207-228. Doi I0.I I I I/j. I467-9469.2006.00524.x.

Koenig, M.A., Zablotska, I., Lutalo, T., Nalugoda, F., Wagman, J., and Gray, R.(2004). Coerced first intercourse and Reproductive Health among adolescent women in Rakai, Uganda, International Family Planning Perspectives, 30 (4) I56-I63.

Lion, K.C., Prata, N. and Stewart, C. (2009). Adolescent child-bearing in Nicaragua: A quantitative assessment of associated factors, International Perspectives on Sexual and Reproductive Health, 35 (2).

Magrath N., Nyirenda M., Hosegood V., and Newell M-L. (2008). Age at first sex in Rural South Africa, Sexually transmitted infections, 85 (Suppl I) 149155.

Manda S. and Meyer R. (2005). Age at first marriage in Malawi: A Bayesian multi-level analysis using a discrete time-to-event model, Journal of the Royal Statistical Association, 168, Part II, 439-455.

Muharaj P. and Munthree C.(2007). Coerced first sexual intercourse and selected reproductive health outcomes among young women in Kwazulu Natal, South Africa, Journal of BioSocial Sciences, 39 (2) 23I-244

Nkurunziza, H. Gebhhardt, A.and Pilz, J.(20I I). Geoadditive modelling of Malaria in Burundi, Malaria Journal I0. I I86/I475-2875-I0-234.

Olubiyi, A.O. and Olubusoye, O.E. (20I3). A new approach of presenting the predictor in a geoadditive model, American Journal of Science Industrial Research, 4 (5) 438-448.

Pettifor A.E., van de Straten A., Dunbar M.S., Shiboski S.C. and Padian N. (2004). Early age of first sex: A risk factor of HIV infection among women in Zimbabwe, AIDS, I 8 (I0) I435-I442

Sandfort T.G.M, Orr M. Hirsch J.S. and Santelli J. (2008). Long term health correlates of sexual debut: Results from a National US Study, American Journal of Public Health, 98 (I) I55-I6I.

Seiving,R.E., Eisenberg, M.E., Petigell, S., and Skay, C.(2006). Friends' influence on adolescent first sexual intercourse, Perspectives on sexual and reproductive health, 38 (I) I3-19

Slaymaker, E., Bwanika, J. B.,Kasamba I., Lutalo T. and Todd, J.(2009). Trends in age at first sex in Uganda: Evidence from Demographic and Health Survey data and longitudinal cohorts in Masaka and Rakai, Sexually Transmitted Infections, 85, il 2-il9 doi: 10.1 |36/sti.2008.034009.

Tilahun, M., and Ayele, G.(20I3). Factors associated with age at first sexual initiation among youths in Gamo Gofa, South West Ethiopia: A crosssectional study, BMC Public health, 13 (662) doi: I0 | |86/ I47|-2458-| 3-622.

Upadyay, D.U. and Hindin, M.J. (2007). The influence of parents' marital relationship and Women's status on children's age at first sex in Sebu, Phillipines, Studies in Family Planning, 38 (3) I73186

Utham, O.A. (2008). Geographical variations and contextual effects on age of initiation of sexual intercourse among women in Nigeria: A multilevel spatial analysis, International Journal of Health Demographics, 7 (27) doi 10.1 I86/1476072x-7-27.

Wand,H., Whitaker, C.and Ramjee,G. (20II). Geoadditive models to assess spatial variation of HIV infections among women in local communities of Durban, South Africa, International Journal of Health Geographics, 10 (28) doi 10.1 I86/1476072x-10-28.

Zaba, B., Isingo, R., Wringe, A., Marston, M., Slaymaker, E. and Urassa, M. (2008).Influence of 
timing of sexual debut and first marriage on sexual behavior in later life: findings from four survey rounds in the Kisesa cohort in Northern Tanzania, Sexually Transmitted infections, 85, i20-26 doi:10.1 |36/sti.2008.033704.

Zaba, B., Pisani, E., Slaymaker, E., and Boerma, J.T. (2004). Age at first sex: understanding recent trends in African Demographic Surveys, Sexually transmitted infections, 80: ii28 - ii35

Guo, W., Wu, Z. Qiu,Y. Chen, G. and Zheng, X. (20I2). The Timing of Sexual Debut Among Chinese Youth, International Perspectives on Sexual and Reproductive Health, 38(4):196-204, doi: $10.1363 / 3819612$

Martinez G., Copen, C.E., Abma, J.C. (20II). Teenagers in the United States: Sexual activity, contraceptive use, and childbearing, 2006-2010 National Survey of Family Growth. National
Center for Health Statistics. Vital Health Stat 23(3I).

Mmbaga, E.J., Leonard, F., Leyna, G.H. (20/2) Incidence and Predictors of Adolescent's Early Sexual Debut after Three Decades of HIV Interventions in Tanzania: A Time to Debut Analysis. PLoS ONE 7(7): e4I700. doi: 10.137I/journal.pone.004 I 700.

Dude, A. (2005)Patterns of Marriage, Sexual Debut, Premarital Sex, and Unprotected Sex in Central Asia, Proceedings of the Population Association of America,

http://paa2005.princeton.edu/papers/5025I

Fahrmeir, L., Tutz, G. (200I) Multivariate Statistical Modelling Based on Generalized Linear Models. Springer, New York. 